\title{
Study to assess the acceptability and feasibility of cervical cancer screening using visual inspection with acetic acid and treatment of precancerous lesions using cryotherapy in low resource settings
}

\author{
Tosha M. Sheth*, Nandita Maitra
}

Department of Obstetrics \& Gynecology, Medical College and SSG Hospital, Vadodara, Gujarat, India

Received: 26 June 2014

Accepted: 5 July 2014

*Correspondence:

Dr. Tosha M. Sheth,

E-mail: drtoshasheth@gmail.com

(C) 2014 Sheth TM et al. This is an open-access article distributed under the terms of the Creative Commons Attribution Non-Commercial License, which permits unrestricted non-commercial use, distribution, and reproduction in any medium, provided the original work is properly cited.

\begin{abstract}
Background: Objective of current study was to assess the acceptability and feasibility of cervical cancer screening using VIA, and treatment of precancerous lesions using cryotherapy in low resource settings

Methods: 526 women from three primary health centers of Shinor taluka (population based approach) and 250 women of Medical College, Vadodara (facility based approach) were sensitized and screened for cervical cancer. Visual Inspection with Acetic acid (VIA) was performed as the screening test. In the population based approach, VIA positive women were referred to a Community Health Centre (CHC) for colposcopy and biopsy. Ablative treatment in the form of cryotherapy was offered. Patients requiring higher forms of treatment were referred to medical college, Vadodara. In the facility based approach, VIA positive women underwent colposcopy. Guided biopsy was performed in those with positive lesions on colposcopy. Cryotherapy was offered in the same sitting. Those not suitable for cryotherapy were offered loop electrosurgical excision procedure. Women found to have invasive cancer were offered definitive management.

Results: VIA positivity rate was $18.8 \%$ in the population based approach and $27.2 \%$ in the facility based approach.58.8\% women in the population based approach and $77.77 \%$ women in the facility based approach were treated with cryotherapy on the same day as screening and none reported any severe side effects. Dropout rate in the community approach was $32.32 \%$ whereas in the facility it was $0.4 \%$.

Conclusions: VIA and cryotherapy procedures were well tolerated by all screened women. This project has shown that the "screen and treat" approach can be successfully implemented in the existing health setup.
\end{abstract}

Keywords: Secondary prevention, Cervical cancer, Colposcopy, Cryotherapy

\section{INTRODUCTION}

Cervical cancer is the third most common cancer among women worldwide, accounting for about 530000 new cases and around 250000 deaths every year. ${ }^{1}$ More than $85 \%$ of the global burden occurs in many developing countries where it is the most common cancer among women and the most common cause of death among middle aged women. ${ }^{1,2}$ The majority of cancers (over $80 \%$ ) in developing countries are detected in late stages, predominantly due to lack of information about cervical cancer and its prevention services. ${ }^{1,2}$ Invasive cervical cancers are preceded by a long phase of precancerous lesions that can be detected by screening and treated by simple and effective treatments. Cervical cancer is thus potentially preventable, and effective screening programmes can lead to a significant reduction in the morbidity and mortality associated with this cancer. ${ }^{3}$

In developed countries, regular screening with Pap smear has been shown to effectively lower the risk for developing invasive cervical cancer, by detecting 
precancerous changes. Despite its public health importance there are no effective prevention programs in most developing countries and hence the risk of disease and death from cervical cancer remains largely uncontrolled. Only $5 \%$ of women in developing countries have ever been screened for cervical abnormalities. ${ }^{4}$ This is because there are too few trained and skilled professionals to implement such a programme effectively. In addition, healthcare resources are not available to sustain such a programme. ${ }^{5}$ In virtually all developing countries, cytology-based services are confined to teaching hospitals or private laboratories in urban areas. Furthermore, delays in reporting cytology results make it less likely that test positive women ever receive their results, let alone treatment or follow-up. These are some of the barriers that prevent cytologybased screening programmes from being effective in developing countries. ${ }^{6}$

Visual Inspection with Acetic acid (VIA), based on the ability of healthcare personnel to detect aceto-white areas on the transformation zone of the cervix, is currently being evaluated as an alternative to the Pap test. Recent studies have demonstrated that Visual Inspection with Acetic acid (VIA) is an alternative sensitive screening method. ${ }^{7,8}$ It is cheap and non-invasive, and can be done in a low level health facility like a health centre. ${ }^{9}$ More importantly, VIA provides instant results, and those eligible for treatment can receive treatment of the precancerous lesions using cryotherapy on the same day and in the same health facility. This "see and treat" method ensures adherence to treatment soon after diagnosis, hence stemming the problem of failing to honour patient referrals. ${ }^{10-12}$

Cryotherapy as a method of treatment for precancerous lesions is effective ${ }^{13,14}$ and easier to implement than other treatment modalities such as Loop Electrosurgical Excision Procedure (LEEP) and cone biopsy. Furthermore, it has additional advantages, including the fact that it is affordable; there is no need for complicated equipment (although a supply of electricity is needed); and it can be done by less specialized personnel and thus can be implemented in a Primary Health Centre (PHC) setting. ${ }^{15}$ Secondary prevention of cervical cancer through screening and treatment of precancerous lesions of the cervix is associated with an overall reduction of morbidity and mortality due to cancer of cervix..$^{13,16,17}$ So, we, in collaboration with the Vadodara district cancer control programme sought to demonstrate the feasibility and acceptability of prevention and treatment of cervical cancer in a resource-constrained setup in Vadodara district, Gujarat, India using VIA and cryotherapy. This was an operational research project. An approval by the hospital ethics committee was obtained prior to commencing the study.

\section{METHODS}

The study was performed in two settings
A. Population based setting - at 3 Primary Health Centres (PHCs) of Shinor taluka, Vadodara district, Gujarat, India.

B. Facility based setting - at SSG hospital, department of obstetrics and gynecology, medical college, Vadodara.

The specific objectives of this project were to:

1. Create awareness about cervical cancer, its effects and the availability of prevention services among women.

2. Assess the acceptability of cervical cancer screening using VIA, and treatment of precancerous lesions using cryotherapy in the population based and the facility based setup.

3. Assess the feasibility of the "screen and treat" approach in the prevention of cervical cancer.

4. Assess why the existing screening programme for cervical cancer has been unable to make a significant impact on disease control in our setup

\section{Population based approach}

This was implemented in an administrative block of 70000 populations in Vadodara district across three primary health centers. Eligible participants were healthy women in the age group of 30-59 years. Pregnant women, postpartum women (less than 12 weeks postpartum) and women with known cervical cancer were excluded. The women were sensitized about the prevention, screening and early detection for cervical cancer. They were mobilized to the nearest PHC every Saturday for screening by VIA. Women received information about the VIA test, how it is done and what to expect during the screening procedure. The screening was performed by trained Auxiliary Nurse Midwives (ANMs) under supervision of a medical officer. A positive VIA test was defined as any aceto-white lesion at the squamocolumnar junction of the cervix. VIA positive women were then referred to the Community Health Center (CHC) for confirmation of diagnosis by colposcopy, punch biopsy and treatment of lesion using cryotherapy. An informed consent was obtained from each woman prior to VIA and cryotherapy. Women who had cryotherapy were counselled about expected side effects, such as cramping, vaginal discharge and spotting and advised about self-care at home and to return for follow up after 12 months to assess the regression of lesions. Women were given analgesics to relieve cramping. In addition, they were counselled to either abstain from sexual intercourse for four weeks following cryotherapy or to use condoms to reduce the risk of cervical infection. Women were asked to record any side-effects or symptoms of complications. Women were advised to report immediately if they experienced symptoms such as fever for more than 2 days, severe abdominal pain, heavy bleeding unrelated to menses, or bleeding with clots. Women not suitable for cryotherapy were referred to medical college, Vadodara for Loop Electrosurgical 
Excision Procedure (LEEP). Criteria for ineligibility for cryotherapy were:

- Aceto-white lesions occupying more than $75 \%$ of the cervix or extending more than $2 \mathrm{~mm}$ beyond the outer limit of the standard cryotherapy probe.

- A lesion extending onto the vaginal wall or more than 2 $\mathrm{mm}$ into the cervical canal.

Those women found to be suspicious for cancer were referred to the medical college hospital for definitive management. Treated women were then asked to return for follow up after one year. VIA negative women were advised to come for screening after an interval of 5 years as recommended by National Cancer Control Programme. (NCCP). ${ }^{18}$

\section{Facility based approach}

Two hundred and fifty women attending the gynecology OPD of SSG hospital, Vadodara underwent VIA. Pregnant women, postpartum women and women with known cervical cancer were excluded. VIA positive women then underwent colposcopy. Women with colposcopic abnormalities underwent a guided biopsy. Endo-Cervical Curettage (ECC) was performed in patients with unsatisfactory colposcopy or when upper limit of lesion could not be visualized. Cryotherapy was offered in the same sitting in appropriate women. Those not suitable for cryotherapy were advised to return for LEEP. Women found to have invasive cancer were offered definitive management.

Data was entered in an excel sheet. Analysis was performed at the end of the study.

\section{RESULTS}

\section{Population based approach}

At PHC Sadhli, 53 out of 300 women tested VIA positive giving a VIA positivity rate of $17.6 \%$. At PHC Simli, 29 out of 124 women tested VIA positive with a VIA positivity rate of $23.3 \%$. At PHC Shinor, 17 out of 102 women tested VIA positive with a VIA positivity rate of $16.6 \%$.So, in the population based setup, a total of 99 out of 526 women screened tested VIA positive, 426 women were VIA negative, 1 was suspicious for cancer. The VIA positivity rate was $18.8 \%$ (Table 1 ). Of the 99 VIA positive women, 67 women reached the $\mathrm{CHC}$ for colposcopy and biopsy while 32 women did not proceed to $\mathrm{CHC}$ due to logistic and other difficulties resulting in a dropout rate of $32.32 \%$ (Table 2). Eighteen out of 67 women had colposcopic abnormality and one woman had a lesion suspicious for cancer. In 17 out of these 18 women, a cryotherapy procedure was performed (Table 3). One woman who was suspicious for cancer was referred to medical college, Baroda for further management where she underwent a radical hysterectomy.

Table 1: Outcome of screening using VIA.

\begin{tabular}{|c|c|c|c|}
\hline Health facility & $\begin{array}{l}\text { No. of } \\
\text { women } \\
\text { screened }\end{array}$ & $\begin{array}{l}\text { VIA } \\
\text { positive }\end{array}$ & $\%$ positivity \\
\hline \multicolumn{4}{|c|}{ Population based approach } \\
\hline PHC Sadhli & 300 & 53 & 17.6 \\
\hline PHC Simli & 124 & 29 & 23.3 \\
\hline PHC Shinor & 102 & 17 & 16.6 \\
\hline \multicolumn{4}{|c|}{ Facility based approach } \\
\hline SSG hospital & 250 & 68 & 27.2 \\
\hline
\end{tabular}

Table 2: Dropout rate after primary screening.

\begin{tabular}{|llll|}
\hline Health facility & $\begin{array}{l}\text { No. of } \\
\text { patients } \\
\text { referred to } \\
\text { next level }\end{array}$ & $\begin{array}{l}\text { No. of } \\
\text { cases that } \\
\text { reached }\end{array}$ & Dropout \% \\
\hline Population based approach & \\
\hline PHC Sadhli & 53 & 38 & 28.3 \\
\hline PHC Simli & 29 & 21 & 27.6 \\
\hline PHC Shinor & 17 & 8 & 53 \\
\hline Facility based approach & & \\
\hline SSG hospital & - & - & $0.4 \%(1 / 250)$ \\
\hline
\end{tabular}

Table 3: Outcome of the VIA positive cases in each setup.

\begin{tabular}{|llllll|} 
Health facility & $\begin{array}{l}\text { No. of } \\
\text { colposcopies } \\
\text { done }\end{array}$ & $\begin{array}{l}\text { Abnormal } \\
\text { colposcopy }\end{array}$ & $\begin{array}{l}\text { Suspicious } \\
\text { for cancer }\end{array}$ & $\begin{array}{l}\text { Biopsies } \\
\text { taken }\end{array}$ & $\begin{array}{l}\text { Cryo } \\
\text { done }\end{array}$ \\
\hline Population based approach & & & 10 & 10 \\
\hline PHC Sadhli & 38 & 10 & 0 & 5 & 5 \\
\hline PHC Simli & 21 & 6 & 1 & 2 & 2 \\
\hline PHC Shinor & 8 & 2 & 0 & & 45 \\
\hline Facility based approach & & & 57 & 45 \\
\hline SSG hospital & 68 & 51 & 6 & & \\
\hline
\end{tabular}


A cryotherapy procedure was performed on the same day as VIA in five out of ten $(50 \%)$ women at PHC Sadhli, in three out of five women $(60 \%)$ at PHC Simli and in two out of two (100\%) women at PHC Shinor (Table 5). None of the women undergoing cryotherapy at any of the three PHCs reported any serious side effects (Table 6).

\section{Facility based approach}

Sixty eight of the 250 screened women tested positive for VIA in the outpatient department giving a screen positive rate of $27.2 \%$ (Table 1). All subjects consented for colposcopy; 57 out of these 68 women had positive findings on colposcopy. All women consented for biopsy (Table 3). In all 57 cervical biopsies were taken, of which $32(56.14 \%)$ were reported as inflammatory, $6(10.52 \%)$ as CIN-I and $6(10.52 \%)$ as invasive carcinoma and the remaining $13(22.8 \%)$ as normal.

One woman out of 250 was lost to follow up with a dropout rate of $0.4 \%$ (Table 2).

Table 4: Treatment modalities offered at the facility based setup.

\begin{tabular}{|ll|}
\hline Treatment modality & $\begin{array}{l}\text { No. of } \\
\text { subjects }\end{array}$ \\
\hline Cryotherapy & 45 \\
\hline Leep & 2 \\
\hline Leep followed by ATH & 1 \\
\hline Abdominal total hysterectomy & 1 \\
\hline Radical surgery (Werthiem's hysterectomy) & 2 \\
\hline
\end{tabular}

A variety of treatment options were available to the patients of the facility based setup based on the requirement. In all 45 cryotherapy procedures and two
Loop Electrosurgical Excision Procedures (LEEP) were performed. One patient underwent a LEEP followed by an Abdominal Total Hysterectomy (ATH). One patient underwent LEEP followed by a radical surgery. Two women underwent an abdominal total hysterectomy. Five women underwent a modified radical hysterectomy (Wertheim's hysterectomy) (Table 4).

Thirty five out of fourty five women $(77.7 \%)$ underwent cryotherapy on the same day as VIA (Table 5). None of the women undergoing cryotherapy reported any serious side effects (Table 6).

Table 5: Time lag between via and cryotherapy.

\begin{tabular}{|c|c|c|c|}
\hline Health facility & Same day & 1-7 days & 8-30 days \\
\hline \multicolumn{4}{|c|}{ Population based approach } \\
\hline PHC Sadhli & 5 & 3 & 2 \\
\hline PHC Simli & 3 & 2 & 0 \\
\hline PHC Shinor & 2 & 0 & 0 \\
\hline \multicolumn{4}{|c|}{ Facility based approach } \\
\hline SSG hospital & 35 & 6 & 4 \\
\hline
\end{tabular}

Table 6: Side effects reported after cryotherapy.

\begin{tabular}{|llll|}
\hline Health facility & $\begin{array}{l}\text { No of } \\
\text { cryotherapies } \\
\text { done }\end{array}$ & $\begin{array}{l}\text { Nomen } \\
\text { reporting } \\
\text { mild side } \\
\text { effects }\end{array}$ & $\begin{array}{l}\text { Nomen } \\
\text { reporting } \\
\text { severe side } \\
\text { effects }\end{array}$ \\
\hline Population based approach & & \\
\hline PHC Sadhli & 10 & 3 & 0 \\
\hline PHC Simli & 5 & 1 & 0 \\
\hline PHC Shinor & 2 & 0 & 0 \\
\hline Facility based approach & & \\
\hline SSG hospital & 45 & 5 & 0 \\
\hline
\end{tabular}

Table 7: Population based approach - summary of services.

\begin{tabular}{|c|c|c|c|c|c|c|c|c|c|c|c|c|}
\hline \multirow{3}{*}{ PHC } & \multirow{3}{*}{$\begin{array}{l}\text { Sessions } \\
\text { organized }\end{array}$} & \multirow{3}{*}{$\begin{array}{l}\text { VIA } \\
\text { done } \\
\text { (No.) }\end{array}$} & \multirow{3}{*}{$\begin{array}{l}\text { VIA } \\
+ \text { ve }\end{array}$} & \multicolumn{6}{|c|}{ Action at $\mathrm{CHC}$} & \multirow{3}{*}{$\begin{array}{l}\text { Punch } \\
\text { biopsy } \\
\text { taken }\end{array}$} & \multirow{3}{*}{$\begin{array}{l}\text { Cryo- } \\
\text { therapy }\end{array}$} & \multirow[b]{3}{*}{ Referral } \\
\hline & & & & \multirow{2}{*}{$\begin{array}{l}\text { Cases } \\
\text { reached } \\
\text { at } \mathrm{CHC}\end{array}$} & \multirow{2}{*}{$\begin{array}{l}\text { Colpo- } \\
\text { scopy } \\
\text { done }\end{array}$} & \multicolumn{4}{|l|}{ Result } & & & \\
\hline & & & & & & $\begin{array}{l}\text { Follow } \\
\text { up } \%\end{array}$ & $+\mathrm{ve}$ & $\begin{array}{l}\text { Suspicio-us } \\
\text { for } \mathrm{CaCx}\end{array}$ & Others & & & \\
\hline Sadhli & 28 & 300 & 53 & 38 & 38 & $71.6 \%$ & 10 & 0 & 1 & 10 & 10 & 0 \\
\hline Simli & 16 & 124 & 29 & 21 & 21 & $72.4 \%$ & 6 & 1 & 1 & 5 & 5 & 1 \\
\hline Shinor & 16 & 102 & 17 & 8 & 8 & $47 \%$ & 2 & 0 & 0 & 2 & 2 & 0 \\
\hline Total & 60 & 526 & 99 & 67 & 67 & $67.6 \%$ & 18 & 1 & 2 & 17 & 17 & 1 \\
\hline
\end{tabular}

Table 8: Facility based approach - summary of services.

\begin{tabular}{|c|c|c|c|c|c|c|c|c|c|c|c|}
\hline $\begin{array}{l}\text { No. of } \\
\text { subjects }\end{array}$ & $\begin{array}{l}\text { VIA } \\
\text { done }\end{array}$ & VIA resul & & & $\begin{array}{l}\text { Colposcopy } \\
\text { done }\end{array}$ & Colp & scopy & & Treatment & & \\
\hline 250 & 250 & VIA +ve & VIA -ve & VIA SC & 68 & +ve & -ve & $\mathrm{SC}$ & Cryotherapy & LEEP & Surgery \\
\hline & & 62 & 182 & 6 & & 51 & 11 & 6 & 45 & 2 & 9 \\
\hline
\end{tabular}

VIA - Visual Inspection with Acetic Acid, SC - Suspicious for Cancer, LEEP - Loop Electrosurgical Excision Procedure 


\section{DISCUSSION}

Cervical cancer is a major public health problem in developing countries that needs to be addressed by exploring the use of alternative screening methods rather than a cytology based system. Sensitivity of VIA to detect CIN2 and CIN3 lesions and invasive carcinoma varies from $37-95 \%$ and specificity from $49-97 \% .{ }^{19}$ The negative predictive value of VIA is sufficiency high to assure screen negative women. ${ }^{19}$

This project was conducted at a district hospital and three lower-level health facilities in the catchment area of the referral hospital where VIA and cryotherapy or VIA alone were performed. This project shows how VIA and cryotherapy, using a "see and treat" or "single visit" approach, can be provided in low-resource settings where the demand for cervical cancer screening services is high and services are currently not available. The VIA-based "see and treat" approach is feasible and acceptable; and the procedures are safe and effective.

The immediate availability of results in case of VIA is a great logistic advantage. The single visit approach has great advantage facilitating diagnosis and treatment in the same visit. In this study, in the population based setup, VIA was performed at PHC level followed by referral to CHC for further diagnosis \& treatment. This was probably the cause for the high dropout rate of $32.32 \%$. This can be overcome if facilities for colposcopy and cryotherapy can be made available at the site of primary screening. Thus population based screening using a 'single visit approach' can offer screening facilities to a larger section of the population with a considerable decrease in the dropout rate.

The facility based approach catered to a smaller number of women presenting to the gynecology clinic with varied complaints. However, as the entire screening and treatment facilities were available at a single centre, loss to follow up was minimal. Besides, various forms of treatment modalities could be offered according to the histopathology reports and clinical staging of the disease.

One of the barriers to accessing screening in low-resource countries like India is limited knowledge among community members about cervical cancer. Efforts to improve awareness of the target population can result in early detection of precancerous lesions, leading to improved survival from cervical cancer in developing countries. This project helped to create awareness in communities about cervical cancer and its prevention by a combination of community-based and facility-based strategies.

As regards the acceptability of this form of screening and treatment procedures, VIA and cryotherapy procedures were well tolerated by women and almost all of those who underwent these procedures would recommend them to other women. This project has shown that the "screen and treat" approach can be successfully implemented in the existing reproductive health setup. Screening for precancerous lesions using VIA, and treatment with cryotherapy, is acceptable and feasible at low-level health facilities.

VIA and cryotherapy have been incorporated in the existing reproductive health services as per the guidelines of the National Cancer Control Programme. However, to optimize the use of VIA and cryotherapy for cervical cancer-prevention programmes, training of adequate number of providers will be needed, along with sustainable supervision and supply and maintenance of equipment and consumables. This project helped to understand that strengthening of services and follow-up of women is critical for the successful implementation of the screening programme. Moreover, frequent and repeated training of the health care providers in performing VIA and cryotherapy is essential to maintain a good quality of screening services.

Scaling-up such a programme will facilitate extension of cervical cancer-prevention services to the target population in both urban and rural areas through development of referral linkages with high-level health facilities. Recommendations provided as a result of this study enabled us to understand how the existing national cancer control programme can be more effectively implemented. Information gathered during site visits indicated that the sites offering VIA have had an increase in the number of women seeking services. Providers who were interviewed reported increased levels of awareness about cervical cancer among communities in the catchment areas, as reflected by increased demand for VIA services. Thus counselling component for VIA and cryotherapy should be strong for successful implementation of this programme. In this project, there was a high rate of client and provider satisfaction with VIA and cryotherapy.

Most women did not report any procedure-related discomfort. Some providers attributed this to good counselling about the discomfort before the procedures. Evaluation of the post-VIA and cryotherapy findings indicated that women welcome VIA because it allows them to know the results and the "next steps" immediately, in a single visit.

VIA is better than a Pap test because women do not have to wait or come back for their results. Moreover, lower cost and immediacy of receiving results as two key benefits of the approach.

Thus, VIA and cryotherapy can be provided at lowerlevel health facilities, provided there is access to a referral facility.

The availability of both VIA and cryotherapy at the Primary Health Centre (PHC) level and establishment of referral and follow-up systems will be critical in order to reduce the number of test-positive women lost to followup. 


\section{CONCLUSION}

VIA is an attractive alternative to cytology-based screening in low resource settings. Similarly, cryotherapy has been selected as the treatment option for eligible test positive individuals. This project provided an important experience in establishing the feasibility and acceptability of these procedures in the existing health care setup. We were satisfied with the alternative approach, as were the women who were screened and treated.

Population based screening was available to a large number of asymptomatic women. However, loss to follow up while being referred from $\mathrm{PHC}$ to $\mathrm{CHC}$ was high $(32.32 \%)$. Facility based approach catered to a small number of symptomatic women. As it was based on a single visit "screen and treat" approach, the dropout rate was negligible. Thus, in the present scenario where population based screening has not been implemented on a large scale, a mix of both approaches is advisable.We noted that funding shortages, limited human resources and lack of supervision are some of the factors that may detract from sustaining and scaling-up such a screening programme. To optimize the use of VIA and cryotherapy for cervical cancer-prevention programme in our setup, a dedicated approach with adequate number of health care providers along with adequate funds and constant training and supervision of providers is needed.

\section{ACNOWLEDGEMENTS}

We are deeply grateful to the members of Vadodara district cancer control programme and the chief district health officer in particular for their kind cooperation.

The need for providing doorstep services to people in rural India and training rural health workers to motivate every pregnant woman to seek expert care during her pregnancy cannot be overemphasized and must be undertaken with utmost priority.

Funding: The study was funded by Vadodara district cancer control programme

Conflict of interest: None declared

Ethical approval: The study was approved by the hospital ethics committee

\section{REFERENCES}

1. Kitando H. Cancer of the cervix: knowledge and attitudes of female patients admitted at Muhimbili National Hospital, Dar es Salaam. East Afr Med J. 2002;79:467-75.

2. Bingham A. Factors affecting utilization of cervical cancer prevention services in low resource settings. Salud Publica de Mexico. 2003;45(Suppl 3):S40816.

3. Herdman C. Planning appropriate cervical cancer prevention programs. In: Herdman C, eds. Program for Appropriate Technology in Health (PATH). 2nd ed. Seattle, WA, USA: PATH; 2000: 1-89.

4. Miller A. Cervical cancer screening programmes: managerial guidelines. In: Miller A, eds. WHO Guideline. Geneva: World Health Organization; 1992: 1-50.

5. Blumenthal $P$ et al. Evaluation of supply and demand factors affecting cervical cancer prevention services. In: Blumenthal $\mathrm{P}$ et al., eds. Rio Et Province, Thailand. Baltimore: Jhpiego; 2004: 1-20.

6. Goldie $\mathrm{S}$ et al. Policy analysis of cervical cancer screening strategies in low-resource setting. J Am Med Assoc. 2001;285:3107-15.

7. Gaffikin $L$ et al. Visual inspection with acetic acid as a cervical cancer test: accuracy validated using latent class analysis. BMC Med Res Methodol. 2007;7:36.

8. Sankaranarayanan $\mathrm{R}$ et al. Effect of visual screening on cervical cancer incidence and mortality in Tamil Nadu, India: a cluster randomised trial. Lancet. 2007;370:398-406.

9. Blumenthal $P$ et al. Safety, acceptability, and feasibility of a single-visit approach to cervical cancer prevention in rural Thailand: a demonstration project. In: Blumenthal $\mathrm{P}$ et al., eds. Rio Et Province, Thailand. Baltimore: Jhpiego; 2003: 1-44.

10. Blumenthal $\mathrm{P}$ et al. A qualitative evaluation of the acceptability and feasibility of a single visit approach to cervical cancer prevention. In: Blumenthal P et al., eds. Rio Et Province, Thailand. Baltimore: Jhpiego; 2004: 1-33.

11. Adadevoh $\mathrm{S}$ et al. A qualitative evaluation of the acceptability and feasibility of a single visit approach to cervical cancer prevention in Ghana. In: Adadevoh $\mathrm{S}$ et al., eds. Ghana Group. Baltimore: Jhpiego; 2004: 1-23.

12. Sellors $J$ et al. Screening and management of precancerous lesions to prevent cervical cancer in low resource settings. Asian Pac J Cancer Prev. 2003;4:277-80.

13. Sankaranarayanan $R$ et al. Effect of visual screening on cervical cancer incidence and mortality in Tamil Nadu, India: a cluster randomised trial. Lancet. 2007;370:365-6.

14. Olatunbosun O. Outcome of cryotherapy for cervical intraepithelial neoplasia in a developing country. Int J Gynecol Obstet. 1992;38:305-10.

15. Chirenje ZM et al. A randomised trial of loop electrosurgical excision procedure (LEEP) versus cryotherapy in the treatment of cervical cancer intraepithelial neoplasia. J Obstet Gynecol. 2001;21:617-21.

16. Denny L et al. Screen-and-treat approaches for cervical cancer prevention in low-resource settings: a randomized controlled trial. J Am Med Assoc. 2005;294:2173-81.

17. Blumenthal PD, McIntosh N. Cervical cancer prevention guidelines for low-resource settings. In: Blumenthal PD, McIntosh N, eds. A Guideline. Baltimore: Jhpiego; 2005: 1-1-H-3. 
18. National Cancer Control Programme. Guidelines for cervical cancer screening programme. In: NCCP, eds. Government of India. World Health Organisation Collaborative Programme, 2004-2005. Chandigarh, India: NCCP; 2006: 1-35.

19. Sankaranaryanan R, Basu P, Wesley RS et al. Accuracy of visual screening for cervical neoplasia: results of an IARC Multicentre trial in India and Africa. Int J Cancer. 2004;110:907-13.

DOI: $10.5455 / 2320-1770 . i j \operatorname{rog} 20140940$

Cite this article as: Sheth TM, Maitra N. Study to assess the acceptability and feasibility of cervical cancer screening using visual inspection with acetic acid and treatment of precancerous lesions using cryotherapy in low resource settings. Int J Reprod Contracept Obstet Gynecol 2014;3:615-21. 